\title{
An Empirical Simplification of the Temperature Penman-Monteith Model for the Tropics
}

\author{
E.Y. Kra \\ Agricultural Engineering Department \\ University of Ghana, P.O. Box LG68, Legon \\ E-mail: erickra@ug.edu.gh
}

\begin{abstract}
A simple empirical equation (EPM) is presented to considerably shorten the computational steps required to estimate reference grass evapotranspiration (ETo) in the tropics using the FAO-56 Penman-Monteith equation (TPM) when the only available weather data are those of temperature. Generally EPM predicted TPM ETo with very high efficiencies, achieving statistical performance measures as high as $r^{2}=1.00, E_{1}=0.98, E_{2}=1.00$, MAE $=0.01 \mathrm{~mm} /$ day in tests on data from six locations in four countries in West Africa. EPM was of general form $E T_{o, E P M}=T^{b} R_{s} / k-R_{a}^{\chi} / 17000$, where $E T_{o}=$ reference grass ETo $\left(\mathrm{MJ} \mathrm{m}^{-2} \mathrm{~d}^{-1}\right), T=$ daily average air temperature $\left({ }^{\circ} \mathrm{C}\right), R_{s}=$ estimated solar radiation $\left(\mathrm{MJ} \mathrm{m} \mathrm{d}^{-1}\right), R_{a}=$ computed extraterrestrial radiation $\left(\mathrm{MJ} \mathrm{m}^{-2} \mathrm{~d}^{-1}\right) ; b, k$, and $\chi$, were parameters computed from local latitude and temperature data. The simplicity of EPM is expected to encourage wider usage of TPM ETo estimates which are more accurate than estimates obtained by using locally-uncalibrated versions of simpler ETo models where only temperature data are available.
\end{abstract}

Keywords: Evapotranspiration, FAO-56 Penman-Monteith, Coefficient of efficiency, ETo, Water-use efficiency, Empirical, Reference grass ETo

\section{Introduction}

Reference evapotranspiration (ETo) estimates are very important in irrigation system design and operations. ETo estimates are used to estimate crop evapotranspiration (ETc) rates which are used to determine design peak irrigation system capacities and also irrigation water requirements and irrigation schedules (Keller \& Bliesner, 1990). Because ETc is difficult and expensive to measure directly, it is usually conveniently estimated indirectly from mathematical models using climatic data inputs (Farahani et al., 2007).

Although the most widely accepted mathematical model for reference grass ETo estimation from meteorological data is the FAO-56 Penman-Monteith equation (PM) (Allen et al., 1998), it requires data, apart from temperature data, that are normally measured at few weather stations, even in the developed countries. For some locations the required climate data are available but of questionable quality, especially in developing countries (Droogers \& Allen, 2002). However, as a minimum, many weather stations around the world, even in developing countries, collect temperature data of acceptable quality (Hargreaves \& Allen, 2003). Therefore ETo models that require only temperature data, but are highly accurate, are very useful in data-poor areas of the world.

Where only temperature data are available, the FAO recommends using the temperature-only Penman-Monteith (TPM) version of PM, whereby all the unavailable data are estimated according to certain outlined procedures (Allen et al., 1998). The TPM has been reported to give reliable estimates in several locations around the world (Campbell Scientific, 1998; Jabloun \& Sahli, 2008; Popova et al., 2006). Two other temperature ETo models are the Hargreaves \& Samani (1985) (HG) and the Turc (1961) (TU) models which have been reported to give reliable ETo estimates (Lu et al., 2005; Yoder et al., 2005; Hargreaves \& Allen, 2003), but only after proper local calibration (Gavilan et al., 2006). However because of lack of equipment for proper local calibration of TUand HG, the attractive simplicity of TU and HG, and discouraging complexity of TPM, uncalibrated HG and TU are often used in practice, especially in the developing world.

The goal of this study was to considerably simplify the computation of TPM ETo estimates with little loss of accuracy. The main objective was to develop one single and simpler equation thatwould give essentially the same ETo estimates 
as TPM, but that would be as easy to use as simple temperature-based models such as TU and HG. The single equation, named the Empirical Penman-Monteith equation (EPM), should be applicable to data from other weather stations in West Africa apart from the original development site. EPM should use the same weather data as TPM, and should eliminate more than 10 of the intermediate computations required to apply TPM.

\section{Materials and methods}

The empirical Penman-Monteith equation (EPM) for the temperature Penman-Monteith equation (TPM) was developed using daily temperature data from six weather stations located in four countries in West Africa. The weather and other required data for the Accra site were obtained from the Water Research Institute (WRI) in Accra, while that for the other sites were obtained from TuTiempo (2008) and then processed for spreadsheet use. Where average wind speed data was not available the global average of $2 \mathrm{~m} / \mathrm{s}$ reported in Droogers \& Allen (2002) was assumed.

All the computations were executed in Microsoft Excel XP spreadsheet installed on Microsoft Windows XP operating system on an HP Pavilion dv6000 laptop computer with Intel (R) Core (TM)2 CPU T7200 2.00 GHz, 1.00 GB RAM.

EPM was developed by starting with a simple form of EPM, and then computing two sets of daily reference grass evapotranspiration (ETo) values (one by TPM and the other by EPM), and then tweaking the EPM parameter values using a numerical algorithm to make the EPM results as close as possible to those of TPM. Examination of the temporal plot of the errors informed the addition of other terms to EPM during the development process. Details of the forms of the TPM and EPM equations and the computational procedures are given in the sections that follow.

\subsection{Computation of daily EPM and TPM ETo}

The following parameters were computed for every day of the year from the daily temperature data for each weather station using the indicated equations:

1. Average temperature, $T$, using Eqn. (14);

2. Slope of the saturation vapor pressure versus temperature curve, $\Delta$, using Eqn. (13);

3. Latent heat of vaporization of water, $\lambda$, using Eqn. (16);

4. Psychrometric constant, $\gamma$, using Eqn. (15);

5. Actual vapor pressure, $e_{a}$, using Eqn. (2);

6. Saturation vapor pressure, $e_{s}$, using Eqn. (3);

7. Extraterrestrial radiation, $R_{a}$, using Eqn. (7);

8. Solar radiation, $R_{s}$, using Eqn. (6);

9. Clear sky radiation, $R_{\text {so }}$, using Eqn. (12);

10. Net longwave radiation, $R_{n l}$, using Eqn. (11);

11. Net shortwave radiation, $R_{n s}$, using Eqn. (6);

12. Net radiation, $R_{n}$, using Eqn. (4);

13. TPM reference grass evapotranspiration, $E T_{o, T P M}$, using Eqn. (1);

14. EPM reference grass evapotranspiration, $E T_{o, E P M}$, using the developed EPM equation, Eqn. (19), with guessed initial values for the unknown parameters of the EPM equation.

\subsection{Development of the form of EPM}

After computing the daily values of the parameters in steps 1-14 above, an optimal form of EPM and its optimal parameter values were determined following these steps:

1. The modified coefficient of efficiency, $E_{1}$, for $E T_{o, E P M}$ versus $E T_{o, T P M}$ for the annual set of data was computed using Eqn. (18);

2. The solver function in Microsoft Excel was set up to maximize $E_{1}$ by numerically varying the values of the parameters of EPM at each stage of the development. The constraints were $s=1$, and $c=0$ where $s$, and $c$ are respectively, the slope and intercept of the straight line of the plot of $E T_{o, E P M}$ versus $E T_{o, T P M}$;

3. The optimum values of the EPM parameters were the ones returned by the Microsoft Excel solver;

4. The residual, $E T_{o, T P M}-E T_{o, E P M}$, versus time was plotted and modeled as an additional term to improve the efficiency of the current form of EPM;

5. A new value of $E_{1}$ was computed and a new set of optimal parameter values was numerically determined using the 
solver in Microsoft Excel to maximize the new $E_{1}$;

6. Other simple forms of EPM were experimented with and the selected optimal form of EPM was that which yielded the highest $E_{1}$ values.

\subsection{Calibration and tests of EPM}

After the development of its form using the Accra data, EPM was calibrated for each of the other tropical sites using the following steps:

1. $E T_{o, T P M}$ and $E T_{o, E P M}$ were computed for each day of one year of average daily data;

2. The optimal values of the parameters of EPM were obtained from the numerical solver by optimizing $E_{1}$.

3. The calibrated EPM was tested by using it to compute daily $E T_{o, E P M}$ from fresh data for each site; for each site (except Accra) the 1999-2003 data were used for EPM development while the 2004-2008 were used for testing. For the Accra site the average 1998-2006 data were used for EPM development while 2007 data were used for testing.

4. The statistical performance parameters $E_{1}, E_{2}$, MAE, $r^{2}, m$, and $c$ were computed for the generated $E T_{o, T P M}$ versus $E T_{o, E P M}$ data and compared to their ideal values.

\subsection{FAO-56 Penman-Monteith equation (PM)}

The FAO-56 Penman-Monteith (PM) for evapotranspiration estimation from weather data is

$$
E T_{o, P M}=\frac{0.408 \Delta\left(R_{n}-G\right)+\gamma \frac{900}{(T+273)} u_{2}\left(e_{s}-e_{a}\right)}{\Delta+\gamma\left(1+0.34 u_{2}\right)}
$$

where, $E T_{o, P M}=$ reference grass evapotranspiration $\left(\mathrm{mm} \mathrm{d}^{-1}\right) ; R_{n}=$ net radiation at the crop surface $\left(\mathrm{MJ} \mathrm{m} \mathrm{m}^{-2}\right.$ $\left.\mathrm{d}^{-1}\right) ; \quad G=$ soil heat flux density $\left(\mathrm{MJ} \mathrm{m}^{-2} \mathrm{~d}^{-1}\right) ; T=$ mean daily air temperature at $2 \mathrm{~m}$ above ground $\left({ }^{o} \mathrm{C}\right) ; u_{2}=$ wind speed at $2 \mathrm{~m}$ above ground surface $\left(\mathrm{m} \mathrm{s}^{-1}\right) ; e_{s}=$ saturation vapor pressure $(\mathrm{kPa}), e_{a}=$ actual va por pressure $(\mathrm{kPa}), \Delta=$ slope of vapor pressure-temperature curve $\left(\mathrm{kPa}^{\circ} \mathrm{C}^{-1}\right), \gamma=$ psychometric constant $\left(\mathrm{kPa}^{\circ} \mathrm{C}^{-1}\right)$ Allen et al. (1998). When all the data required to use Eq. 1 is unavailable it can still be applied by using various formulas to estimate the missing data from temperature data; this method of applying PM from only temperature data is called the temperature PM method (TPM) in this study, for which $E T_{o, P M}$ is replaced by $E T_{o, T P M}$ in Eqn. (1).

\subsection{Temperature Penman-Monteith application (TPM)}

TPM was used to estimate daily ETo from the maximum and minimum temperature data following the recommendations of Allen et al., (1998) and (Allen, 2002). In the TPM the daily $e_{s}, e_{a}, R_{n}, R_{s}, R_{n s}, R_{n l}, R_{a}$, $\Delta, \gamma, P$, and $G$ data were all estimated from maximum and minimum temperatures $T_{m}$ and $T_{n}$, respectively, elevation of the site above sea level $(z)$ latitude of the location $(\phi)$, and the Julian day $(J)$, using mathematical expressions.

The actual vapor pressure, $e_{a}(\mathrm{kPa})$, was estimated by

$$
e_{a} \approx 0.6108 \exp \left(\frac{17.27 T_{n}}{T_{n}+237.3}\right)
$$

and saturated vapor pressure, $e_{s}(\mathrm{kPa})$, was estimated by

$$
e_{s} \approx \frac{0.6108}{2}\left[\exp \left(\frac{17.27 T_{x}}{T_{x}+237.3}\right)+\exp \left(\frac{17.27 T_{n}}{T_{n}+237.3}\right)\right]
$$

The net radiation, $R_{n}\left(M J m^{-2} d^{-1}\right)$, was estimated as 


$$
R_{n}=R_{n s}-R_{n l}
$$

where

$$
R_{n s} \approx 0.77 R_{s}
$$

and solar radiation, $R_{s}\left(M J m^{-2} d^{-1}\right)$, was estimated using

$$
R_{s}=k_{R s} \cdot R_{a}\left(T_{x}-T_{n}\right)^{0.5}
$$

with $k_{R s}$ set to 0.19 for locations near large water bodies, and 0.16 for other locations (Hargreaves \& Allen, 2003). $R_{a}$, extraterrestrial radiation ( $M J m^{-2} d^{-1}$ ) was computed from (Duffie \& Beckman, 1991)

$$
\begin{gathered}
R_{a}=\frac{24 \times 60}{\pi} G_{s c} d_{r}\left[\omega_{s} \sin (\phi) \sin (\delta)+\cos (\phi) \cos (\delta) \sin \left(\omega_{s}\right)\right] \\
\delta=0.4093 \sin \left(\frac{2 \pi(284+J)}{365}\right) \\
d_{r}=1+0.033 \cos \left(\frac{2 \pi J}{365}\right) \\
\omega_{s}=\cos ^{-1}(-\tan (\phi) \tan (\delta))
\end{gathered}
$$

where $G_{s c}=$ global solar constant $\left(0.0820 \mathrm{MJ} \mathrm{m}^{-2} \mathrm{~min}^{-1}\right) ; J=$ day of the year $(\operatorname{Jan} 1=1) ; d_{r}$ = relative earth-sun distance; $\omega_{s}=$ sunset hour angle (radians); $\phi=$ latitude (radians); $\delta=$ solar declination (radians).

The net long-wave radiation, $R_{n l}\left(M J m^{-2} d^{-1}\right)$, was estimated from

$$
R_{n l} \approx \sigma \frac{\left(T_{x}+273.16\right)^{4}+\left(273.16+T_{n}\right)^{4}}{2}\left(0.34-0.14 \sqrt{e_{a}}\right)\left(\frac{1.35 R_{s}}{R_{s o}}-0.35\right)
$$

where the clear sky solar radiation, $R_{s o}\left(M J m^{-2} d^{-1}\right)$, was estimated using

$$
R_{s o}=\left(0.75+2 \times 10^{-5} z\right) R_{a}
$$

and $z=$ altitude above sea level (m). $\Delta$ was computed from

$$
\Delta=0.2(0.00738 T+0.8072)^{7}-0.000116
$$

where the average temperature, $T$, was calculated as

$$
T=\frac{T_{n}+T_{x}}{2}
$$

The psychrometric constant, $\gamma$, was calculated from

$$
\gamma=\frac{c_{p} P}{\varepsilon \cdot \lambda}
$$

where $P=$ atmospheric pressure $(\mathrm{kPa}), c_{p}=$ the specific heat at constant pressure, $\left(\mathrm{MJ} \mathrm{kg}^{-1} \mathrm{~K}^{-1}\right), \varepsilon=$ ratio of the molecular weights of water vapor/dry air, and the latent heat of water, $\lambda\left(\mathrm{MJ} \mathrm{kg}^{-1}\right)$ was computed as

$$
\lambda=2.501-0.002361 T
$$

and $P$ at elevation, $z$ m above sea level, was estimated using (Allen, 2002) 


$$
P=101.3\left[\frac{T+273-0.0065 z}{T+273}\right]^{5.26}
$$

Following normal practice for fully vegetated reference grass surface, the approximation $G \approx 0$ was used in this study (Pereira \& Allen, 1999; DehghaniSanij et al., 2004; Jabloun \& Sahli, 2008; Allen et al., 1998; Allen, 2002)

\subsection{Statistical performance measures}

The main measure of the ability of EPM to predict TPM ETo values was the modofied coefficient of efficiency, $E_{1}$, which is related to, but more discriminatory than the coefficient of efficiency, $E_{2}$ (Hall, 2001); In this paper they were defined generallly as $E_{c}$, Bardsley(Bardsley \& Purdie, 2007; Legates \& McCabe, 1999)

$$
E_{c}=1-\frac{\sum_{i=1}^{N}\left|E T_{o, T P M}^{i}-E T_{o, E P M}^{i}\right|^{c}}{\sum_{i=1}^{N}\left|E T_{o, T P M}^{i}-\overline{E T_{o, T P M}^{i}}\right|^{c}}
$$

where $c$ is a positive integer, equal to 1 for $E_{1}$ and 2 , for $E_{2}$. $E_{c}$ ranges from $-\infty$ to 1.00 , with higher values indicating better agreement between model EPM and TPM. If $E_{c}=0$ then the mean of the TPM estimates, $\overline{E T_{o, T P M}^{i}}$, is as good an estimator as model EPM. For further information of the relative merits of $E_{1}, E_{2}$, and the coefficient of determination, $r^{2}$, as measures of model performance the reader is referred to Legates \& McCabe (1999); Yoder et al. (2005); Zhang et al. (2008); Stöckle et al. (2004). The other measures of the performance of EPM were coefficient of determination $\left(r^{2}\right)$, intercept of EPM versus TPM regression line $(c)$, slope of the EPM versus TPM regression line $(m)$, and annual mean absolute error (MAE).

\section{Results and Discussion}

\subsection{General and specific EPM equations}

The general form of the developed EPM equation was

$$
E T_{o, E P M}=E P M p-E P M c=\frac{T^{b} R_{s}}{k}-\frac{R_{a}^{\chi}}{17000}
$$

where $E T_{o, E P M}=$ reference grass evapotranspiration $\left(\mathrm{MJ} \mathrm{m} \mathrm{m}^{-2} \mathrm{~d}^{-1}\right)$ with $k, b$, and $\chi$ being locally calibrated constants and all other symbols as previously defined. $E T_{o, E P M}$ in $\mathrm{mm} \mathrm{d}^{-1}$ was obtained by dividing $E T_{o, E P M}(\mathrm{MJ}$ $\left.\mathrm{m}^{-2} \mathrm{~d}^{-1}\right)$ by the latent heat of vaporization of water, $\lambda\left(\mathrm{MJ} \mathrm{kg}^{-1}\right)$. The calibrated form of eqn. (19) for the WRI site was

$$
E T_{o, E P M}=\frac{T^{0.63} R_{s}}{14}-\frac{R_{a}^{2.54}}{17000}
$$

The optimal parameter values for the six sites during calibration and testing are shown in Table 1

\subsection{Minimizing EPM residuals}

The final form of EPM consisted of two parts, the main part, EPMp, and the minor part, EPMc (see eqn. (19)). The purpose of EPMp was to predict ETo by a very simple mathematical expression while that of EPMc was to minimize the prediction errors (i.e., $E T_{o, E P M}-E T_{o, T P M}$ ) of EPM by modeling the errors of EPMp (i.e., $E T_{o, E P M p}-E T_{o, T P M}$ ). The residuals of EPMp when EPM=EPMp were less precise and of a less definite form (Fig. 1a) than when $\mathrm{EPM}=\mathrm{EPMp}+\mathrm{EPMc}($ Fig. 1b).

The improvement in the $E T_{o, T P M}$ prediction efficiency of EPM by the introduction of EPMc was reflected in the reduced scatter and fluctuation in the temporal residual plots. For example when EPM=EPMp was calibrated with the 
average daily 1998-2006 Accra temperature data, $E_{1}$ was 0.95. But, when EPM=EPMp+EPMc was calibrated with that same temperature data $E_{1}$ increased to 0.99 with the EPM residuals plot almost flattened (Fig. $\left.1 \mathrm{~b}\right)$ compared to the EPM residuals plot of EPM=EPMp (Fig. 1a).

Although initially the residuals of EMP=EPMp were modeled independently and then added as a separate term to the EPMp to form a more efficient EPM equation, no simple expression was found to closely model the EPM=EPMp residuals shown in Fig. 1(a). However, when the old EPMp and the resulting EPMc were then calibrated at the same time (as EPM=EPMp+EPMc), the scatter in the EPMp residuals was reduced and a more definite pattern emerged in the seasonal fluctutions which were then more easily modeled with a simple expression for EPMc. Thus calibrating EPM with both the EPMp and EPMc terms resulted in higher precision and $E_{1}$ values than calibrating EPMp and EPMc separately.

\subsection{Precision and accuracy during calibration}

During calibration the match between EPM and TPM was very good for all the sites as reflected in the performance parameters $m, r^{2}$ and $E_{2}$ being at their best possible values of 1.00. (Table 1). Even though EPM appeared to have performed equally well at all the sites, its performance at the Accra site was best using the $E_{1}$ measure which has a greater power of disrmination than $r^{2}$ and $E_{2}$. However the difference betwen the best $\left(E_{1}=0.99\right)$ and worst ( $E_{1}=0.95$ ) performances at calibration was only $\Delta E_{1}=0.04$. The desirable value of $c=0.00 \mathrm{~mm} \mathrm{~d}^{-1}$ was also achieved at all the sites. Even though the desirable value of $\mathrm{MAE}=0$ was not achieved at any of the sites the worst value was negligible for practical purposes, at $0.03 \mathrm{~mm} \mathrm{~d}^{-1}$.

\subsection{Precision and accuracy under test}

When the calibrated EPM, with the values of $\chi, k$, and $b$ obtained from calibration at each of the six weather stations, was used on new data to predict daily $E T_{o, T P M}$ for one year the values of the performance parameters changed little (Table 1 and Fig. 2). The main measure of performance, $E_{1}$, either remained virtually the same or declined by a maximum of only 0.01 . The values of $r^{2}$ and $E_{2}$ were still as high as at calibration $\left(r^{2}=E_{2}=1.00\right)$. In general the value of $m$ also changed by only 0.01 , except in one case (Abidjan) where it declined by 0.04 . The MAE also remained at the same low value in all but two cases where it declined by just $0.01 \mathrm{~mm} \mathrm{~d}^{-1}$.

At all sites the differences between $E T_{o, E P M}$ and $E T_{o, T P M}$ were so small that although there were as many as 366 points in the linear regression plots of $E T_{o, E P M}$ versus $E T_{o, T P M}$ (Fig. 2) the plotted points were almost indistinguishable from the 1:1 line. While there appears to be large differences between EPM and TPM for ETo values above $5.3 \mathrm{~mm} \mathrm{~d}^{-1}$ in the case of Abidjan, Cote D'Ivoire, it should be pointed out that the maximum difference was only $0.3 \mathrm{~mm} \mathrm{~d}^{-1}$ which occured at $E T_{o, T P M}=6.3 \mathrm{~mm} \mathrm{~d}^{-1}$ versus $E T_{o, E P M}=6.0 \mathrm{~mm} \mathrm{~d}^{-1}$, and that $E_{1}$ for the year was as high as 0.96 . Also, this involved only 8 out of 366 points (i.e., $2 \%$ ) and thus no general conclusions can be drawn from this observation especially since it was not observed for the five other locations.

\subsection{Similarities and differences with other models}

EPM is similar, in form, to simple ETo models that use only temperature and solar radiation input data, such as the Hargreaves (Hargreaves et al., 1985), Turc (Turc, 1961) and Thornthwaite methods (Jacobs \& Satti, 2001), but it is different from those simple models in that it is not another empirical temperature ETo model based on actual ETo data (Hargreaves \& Allen, 2003; Hargreaves \& Samani, 1985; Turc, 1961) but rather simply a shortcut method for estimating daily ETo using the Penman-Monteith equation when the only available data are maximum and minimum temperature data. EPM thus takes the place of the Penman-Moneith equation (eqn. 1) itself, and the nine equations-(2), (3), (4), (5), (11), (12), (13), (15), and (17)-that are used to estimate the unavailable weather data. Therefore EPM is simply an empirical form of the Penman-Monteith equation for use when only temperature data are available and all the other data needed to use PM have to be estimated from temperature data. 


\section{Conclusions}

The empirical Penman-Monteith equation (EPM) developed in this study has a much simpler form than the Penman-Monteith equation. Also several fewer intermediate calculation steps are required to estimate daily reference grass evapotranspiration, ETo, by EPM than by the Penman-Monteith equation when only temperature data are available and EPM is applicable at several sites in tropical West Africa. EPM is not another new ETo equation, but rather simply a less tedius way of estimating Penman-Monteith daily ETo when using only temperature data. For practical purposes there is no difference between the ETo estimates made by EPM and TPM. The most difficult part of applying EPM is the initial calibration for a particular location which can be done easily in Microsoft Excel, after which using EPM becomes as simple as using any of the simple temperature-based ETo models. Those who prefer less accurate ETo estimates from locally-uncalibrated versions of simpler ETo models in order to avoid the more involved computations of the FAO-recommended TPM may find the simplicity of the EPM application of TPM attractive for improving their ETo estimates to achieve higher water-use efficiencies.

\section{References}

Allen, R. (2002). REF-ET: Reference evapotranspiration calculation software for FAO and ASCE standardized equations. University of Idaho. [Online] Available: www.kimberly.uidaho.edu/ref-et/.

Allen, R. G., Pereira, L. S., Raes, D., \& Smith, M. (1998). Crop evapotranspiration - Guidelines for computing crop water requirements. FAO Irrigation and Drainage Paper, No. 56. FAO, Rome.

Bardsley, W. E. \& Purdie, J. M. (2007). An invalidation test for predictive models. Journal of Hydrology, 2007(338), $57-62$.

Campbell Scientific. (1998). Reduced set evapotranspiration station. Application note, Campbell Scientific, Logan Utah.

DehghaniSanij, H., Yamamoto, T., \& Rasiah, V. (2004). Assessment of evapotranspiration estimation models for use in semi-arid environments. Agricultural Water Management, 64, 91-106.

Droogers, P. \& Allen, R. G. (2002). Estimating reference evapotranspiration under inaccurate data conditions. Irrigation and Drainage Systems, 16, 33-45.

Duffie, J. A. \& Beckman, W. A. (1991). Solar engineering of thermal processes. New York: Wiley \& Sons Inc, 2 edition.

Farahani, H. J., Howell, T. A., Shuttleworth, W. J., \& Bausch, W. C. (2007). Evapotranspiration: progress in measurement and modeling in agriculture. Transactions of the ASABE, 50(5), 1627-1638.

Gavilan, P., Lorite, L. J., Tornero, S., \& Berengena, J. (2006). Regional calibration of Hargreaves equation for estimating reference ET in a semi-arid environment. Agricultural Water Management, 81, 257-281.

Hall, M. J. (2001). How well does your model fit your data? Journal of Hydroinformatics, 03.1, 49-55.

Hargreaves, G. H. \& Allen, R. G. (2003). History and evaluation of Hargreaves evapotranspiration equation. J. Irrig. and Drain. Engrg., ASCE, 129(1), 53-63.

Hargreaves, G. H. \& Samani, Z. A. (1985). Reference crop evapotranspiration from temperature. Appl. Eng. Agric. ASAE, 1(2), 96-99.

Hargreaves, G. L., Hargreaves, G. H., \& Riley, J. P. (1985). Irrigation water requirement for Senegal River Basin. $J$. Irrig. and Drain. Engrg., ASCE, 111, 265-275.

Jabloun, M. \& Sahli, A. (2008). Evaluation of FAO-56 methodology for estimating reference Evapotranspiration using limited climatic data application to Tunisia. Agricultural Water Management, 95(2008), 707-715.

Jacobs, J. M. \& Satti, S. R. (2001). Evaluation of reference evapotranspiration methodologies and afsirs cropwater use simulation model. Technical report, Department of Civil and Coastal Engineering University of Florida Gainesville, Florida.

Keller, J. \& Bliesner, R. D. (1990). Sprinkler and Trickle Irrigation. New York: Chapman \& Hall.

Legates, D. R. \& McCabe, G. J. (1999). Evaluating the use of 'goodness-of-fit' measures in hydrologic and hydroclimatic model validation. Water Resources Research, 35, 233-241.

Lu, J., Sun, G., McNulty, S. G., \& Amatya, D. M. (2005). A comparison of six potential Evapotranspiration methods for regional use in the southeastern united states. Journal of the American Resources Association, 41(3), 621-633.

Pereira, L. S. \& Allen, R. G. (1999). CIGR Handbook of Agricultural Engineering Volume I, chapter 5.1: Crop Water Requirements, (pp. 213-262). ASAE.

Popova, Z., Kercheva, M., \& Pereira, L. S. (2006). Validation of the FAO methodology for computing ETo with limited 
data. application to south Bulgaria. Irrig. and Drain., 55, 201-215.

Stöckle, C. O., Kjelgaard, J., \& Bellocchi, G. (2004). Evaluation of estimated weather data for calculating Penman-Monteith reference crop evapotranspiration. Irrig Sci, 2004(23), 39-46.

Turc, L. (1961). Evaluation des besoins en eau d'irrigation, evapotranspiration potentielle, formulae climatique simplifice et mise jour (in French). (English title: Estimation of irrigation water requirements, potential evapotranspiration: A simple formula evolved up to date). Ann. Agron., 12, 13-49.

TuTiempo (2008). Tutiempo weather data website. www.tutiempo.net. Accessed in January 2009.

Yoder, R. E., Odhiambo, L. O., \& Wright, W. C. (2005). Evaluation of methods for estimating daily reference crop evapotranspiration at a site in the humid southeast United States. Applied Engineering in Agriculture, ASAE, 21(2), 197-202.

Zhang, B., Kang, S., Li, F., \& Zhang, L. (2008). Comparison of three evapotranspiration models to Bowen ratio-energy balance method for a vineyard in an arid desert region of Northwest China. Agricultural and Forest Meteorology, 148(2008), 1629-1640.

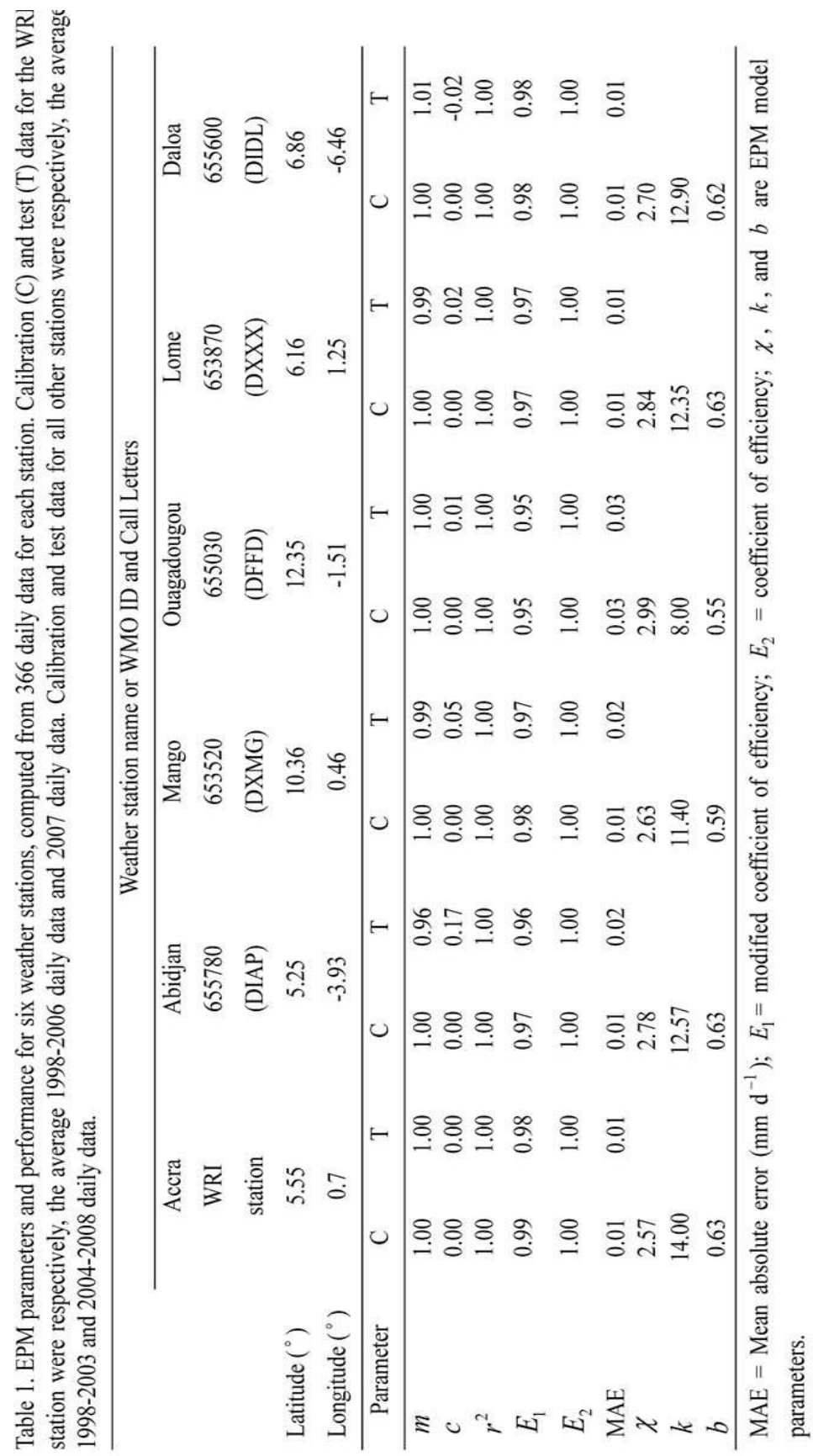




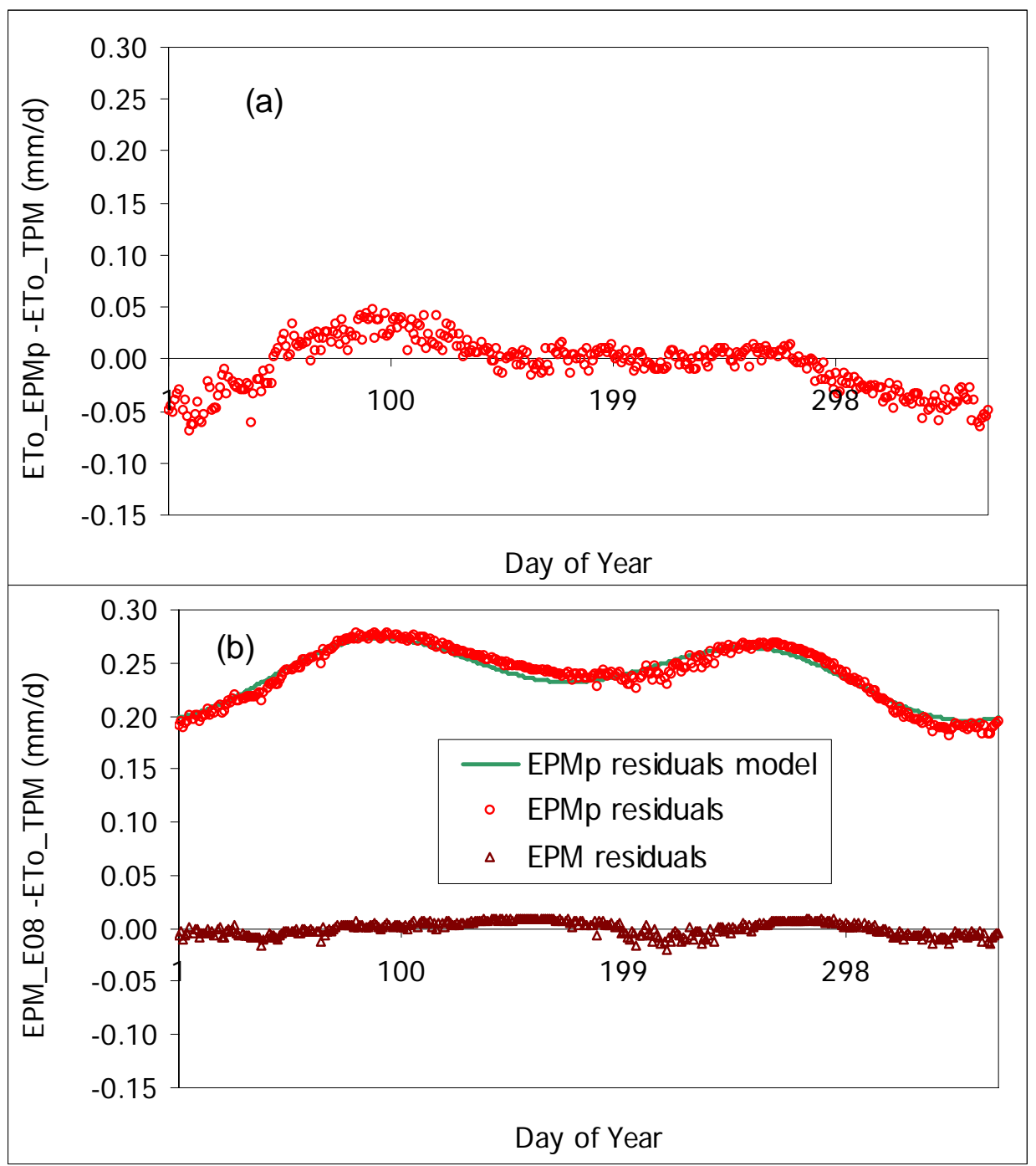

Figure 1. Variations of the daily residuals of the calibrated EPM=EPMp (a) and and of EPM=EPMp+EPMc (b), showing how well EPMc models the modified residuals in the latter case, for the average 1998-2006 data for the WRI weather station. 

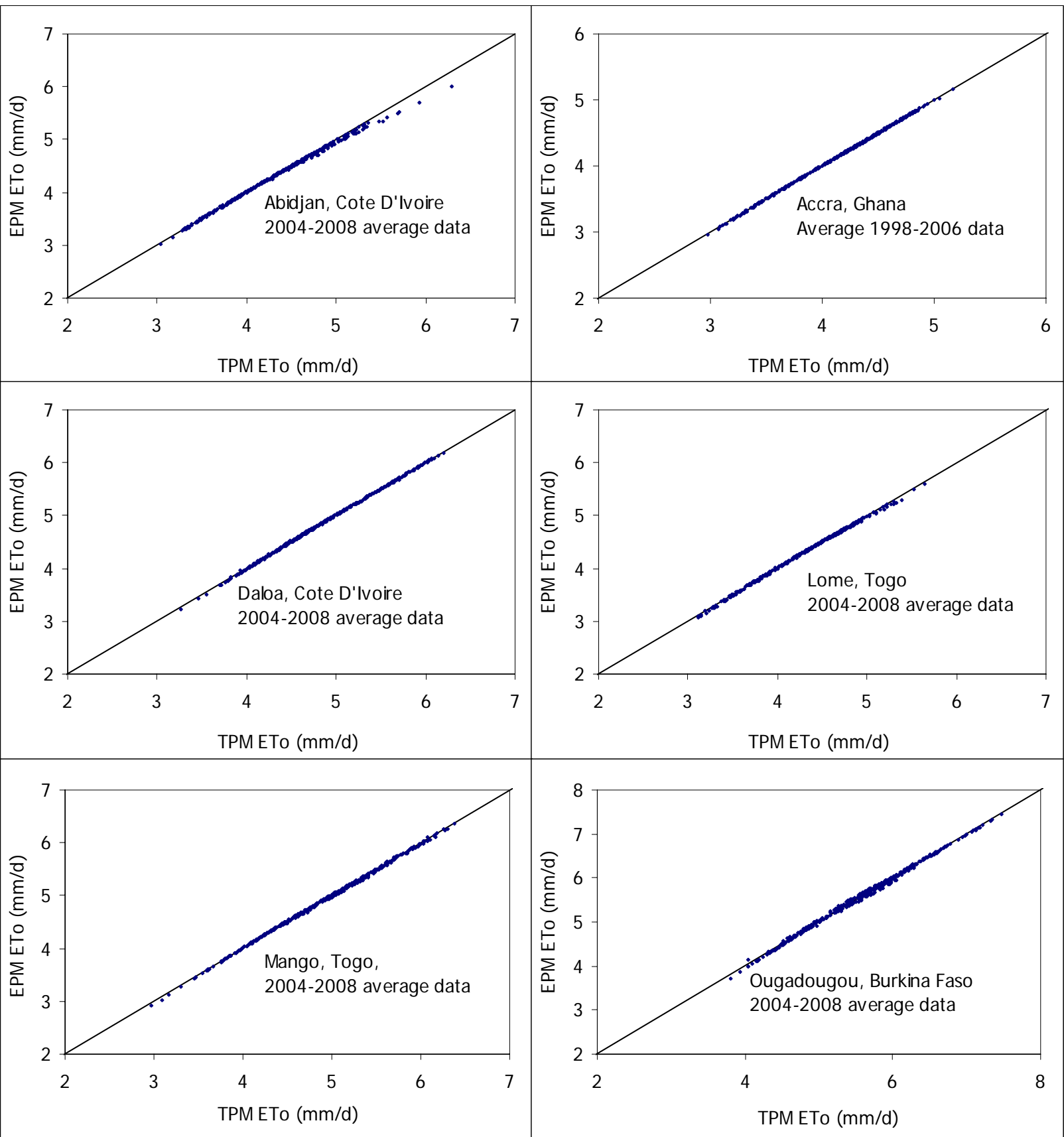

Figure 2. EPM ETo versus TPM ETo for 10-year average daily temperature data for six weather stations in Accra (Ghana), Abidjan (Cote D'Ivoire), Ouagadougou (Burkina Faso), Daloa (Cote D'Ivoire), Lome (Togo), and Mango (Togo). Each plot has 366 data points. 